\title{
A cor aplicada ao corpo: design, fotografia e cultura
}

\section{The color applied to the body: design, photography and culture}

SILVA, Sérgio Antônio

Universidade do Estado de Minas Gerais - UEMG I sas.sergiosilva@gmail.com

\section{Resumo \\ O texto parte da premissa de que o design \\ Abstract}

contemporâneo trabalha numa linha de pensamento que coloca o homem no centro do projeto. Essa concepção vem do livro Uomo al centro del progetto e de um artigo de Flaviano Celaschi intitulado "O corpo como matéria-prima do projeto". Feita essa introdução, o texto define a noção de corpo como um campo de linguagem. Na sequência, aborda o tema da cor do corpo humano e também da cor aplicada ao corpo. Finalmente, propõe a análise de três projetos cujos temas têm a ver com essa relação do corpo com as cores, no campo da fotografia. A intenção é mostrar como cada um dos casos analisados, sob o ponto de vista do design, embora com percursos metodológicos, linguagens e resultados bastante distintos uns dos outros, trabalha a ideia do "corpo como matéria-prima do projeto".

Palavras-chave: Design. Cor. Corpo.

This paper starts from the premise that contemporary design works in a train of thought that puts men in the center of the project. This concept is taken from the book Uomo al centro del progetto and from the essay "The body as a raw material of the project". Firstly, this study defines the notion of body as a stylistic approach. Then, it discusses the color of the human body and the color artistically applied to the body. Finally, it proposes the analysis of three photography projects about the connection of the body with the colors. The intention is to show, from the point of view of design, how each of the cases analyzed - despite their differences in methodology, style, and results - works with the idea of "the body as a raw material of the project".

Keywords: Design. Color. Body. 


\title{
1 INTRODUĈ̣̃O
}

Há uma linha de pensamento do design que coloca o homem - e, por conseguinte, o humanismo - no centro do projeto, sob um ponto de vista sistêmico, em oposição a um pensamento focado, segundo uma lógica produtiva industrial, no produto. E em resposta, por assim dizer, a demandas advindas da própria sociedade, em termos de sustentabilidade, ciclo de vida, reuso etc. Uma linha presente no Politécnico de Torino, por exemplo, cujas diretrizes encontramos no livro Uomo al centro del progetto: design per un nuovo umanesimo, uma edição de 2008, organizada por Claudio Germak, na ocasião do evento Torino 2008 World Design Capital.

\begin{abstract}
A real possibilidade evolutiva do processo produtivo parece agora residir na derrubada dos valores nos quais havíamos sempre acreditado, definindo assim um novo "foco" em que há de se concentrarem as ações futuras, que põe o homem no centro do projeto, o homem que está em relação sistêmica com o mundo circundante. [...] Eis porque o produto possui nesse cenário somente o último dos valores a se colocar em jogo: sem avaliações oportunas de quanto isso seja realmente necessário à existência, sem se dar conta antecipadamente de quanto outros valores são mais importantes para a vida humana, a produção de um objeto perde o sentido. (GERMAK, 2008, p. 14).
\end{abstract}

Por extensão, poderíamos dizer que há uma linha de pensamento, nesse mesmo design italiano, que coloca o corpo no centro do projeto. "A ação [...] do design ou coloca no centro o corpo e sua transformação ou não é design." (CELASCHI, 2016, p. 67). Essa afirmação, assim tão contundente, é de Flaviano Celaschi, um dos autores do livro acima mencionado. A citação, entretanto, foi retirada de um artigo seu de 2016, intitulado, na tradução brasileira, "O corpo como matéria-prima do projeto". Em tempos pós-humanos, o corpo ainda ocupa o centro do projeto.

Mas o que significa "ocupar o centro do projeto"? Há um sentimento de humanidade aí, segundo Celaschi (2016), que vem desde tempos remotos, pré-históricos. Assim, em algum ponto da linha evolutiva humana, um gesto intencional do homem sobre seu próprio corpo - uma pintura, um corte, uma prótese, um sinal - inaugurou algo que poderia ser o grau zero do que hoje chamamos de design. Uma intervenção intencional sobre o corpo, com propósitos místicos, expressivos, lúdicos, utilitários, bélicos etc. que acompanharia o homem, ao longo do tempo e da vida, como sua própria sombra.

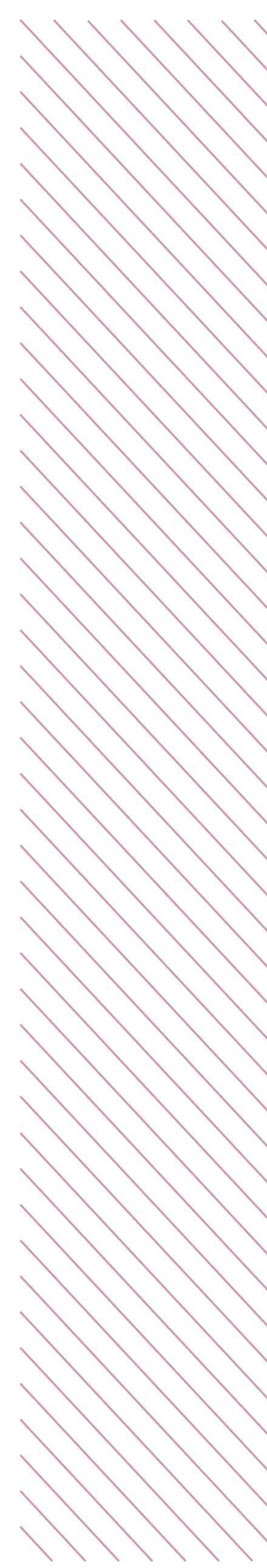


atividade manipuladora intencional do homem. Uma atividade desejada, concebida, realizada e apreciada coletivamente - pois, como disse [Jacques] Lacan, "somos seres olhados no espetáculo do mundo" -, porque feita para comunicar com nós mesmos e com os outros. Uma atividade incessante e transversal a cada cultura, em cada latitude, em cada época conhecida, que poderíamos fazer coincidir com o antecessor do nosso projetar contemporâneo destinado aos artefatos para comercialização (as mercadorias), a que chamamos design. (CELASCHI, 2016, p. 58).

Para Celaschi (2016), o corpo escrito é uma das categorias desse fenômeno. Pinturas, grafismos, tatuagens, escarificações são algumas das ações do homem, primeiro, em seu próprio corpo, depois, no corpo do outro e também em superfícies, com propósitos, ora de comunicação, ora de puro prazer estético, ora, ainda, em cumprimento a algum rito de magia ou crença. A pele, os pelos, partes como lábios, boca, nariz, orelhas sempre são alvo de intervenção. O homem projeta em (e comunica com) seu próprio corpo de diversas formas, há milhares de anos.

O certo é que, a um estranho, aquilo que poderia dar a parecer que estamos vivendo um século exasperadamente dedicado ao controle do corpo por um ideal típico representado pelo cinema ou pela publicidade, não é mais do que a adesão coletiva e globalizada a um particular, talvez diferente do passado, tipo ideal de corpo. Acontece que nos esquecemos de que as técnicas de inscrições no corpo (tatuagem, escarificações etc.) são práticas mnemotécnicas multimilenares que utilizam a pele do corpo como plano para transcrever, na memória do sujeito, situações e eventos que não devem ser esquecidos por toda a vida. (CELASCHI, 2016, p. 66).

A história do corpo e das práticas projetuais a ele associadas - que, no fim, são práticas culturais inseridas em determinado contexto histórico - é longa e complexa; as formas de expressão são extensas', contudo, há, nesse universo das intervenções do homem sobre o (próprio) corpo, um rumo (um método) para pensarmos essas intervenções como práticas projetuais do design. Nesse sentido, propomos, na parte final deste artigo, depois de passarmos por essas breves considerações sobre o corpo como matéria de projeto (e de linguagem,

1

$\mathrm{Na}$ atualidade, o debate em torno da intervenção intencional do corpo tem se intensificado em função dos avanços da tecnologia no ramo das ciências médicas e dos resultados surpreendentes de suas práticas. "Próteses, piercings, tatuagens, cirurgias de mudança de sexo, drogas que potencializam a atenção, a ereção, o humor, lentes maravilhosas que fazem do homem um super-homem, transplantes e cirurgias genéticas, novas formas de nascer e morrer impossível encontrar onde parar essa lista de modificações corporais possíveis." (VERAS, 2017). 
portanto) e sobre a cor relacionada ao corpo, o estudo de caso de obras que, com base na fotografia, adentram o universo do design gráfico e que têm relação com a cor aplicada ao corpo ou, antes, com a própria cor do corpo. Serão analisados três projetos, com o intuito de comprovar como pode ser bemsucedida, na contemporaneidade, uma ideia que, no campo do design ou da arte $^{2}$, reforça o propósito de intervenção intencional no corpo.

Antes, porém, gostaríamos de reafirmar o entendimento do corpo, não só como uma substância física, mas, sobretudo, como construção de linguagem. Sabemos que "o tipo ideal de corpo", como se refere Celaschi, é uma concepção simbólica e imagética. O nosso corpo - e o corpo do outro - não nos pertence, salvo como representação de um corpo ideal, um corpo ora faltoso, ora excessivo, inteiro ou partido. "Não somos nosso corpo em carne e osso, somos o que sentimos e vemos de nosso corpo." Essa é a premissa (impressa na capa, na edição brasileira) do livro Meu corpo e suas imagens, do psicanalista argentino Juan-David Nasio (2009). Dir-se-ia, na psicanálise, que o corpo da linguagem habita o corpo em carne, pele, osso e órgãos. O corpo biológico se junta ao corpo erógeno das sensações, de prazer e gozo.

Só assim, assumindo o entendimento do corpo, a um só tempo, como o corpo sentido (o físico) e o corpo dos sentidos (o corpo-signo), sede de uma imagem de si (lembremos o corpo que vemos e fantasiamos - mais amado, mais odiado, mais bonito, mais feio, perfeito e imperfeito - no espelho), poderemos compreender a importância de se estudar a cor do/no corpo, pensando na aplicação desse estudo no âmbito do design. Pensamos, aqui, na parte visível do corpo como manifestação da (p)arte invisível do desejo; na intervenção intencional, porém segundo registros do inconsciente, no corpo.

\section{CORES CORPÓREAS}

Tal como a cor da pele é variada, também são variados os modos como se interpreta e se dá sentido a esse fenômeno, ao longo da história da humanidade: a cor da pele humana. A cor que vem da queda do pelo do hominídeo que habitava o continente africano. A melanina do homem africano que aos poucos se foi fazendo ausente, à medida que certos grupos passavam a habitar partes mais extremas da Terra, mais distantes dos raios solares.

A cor que, desde há muitos séculos, é signo de diferença individual e suposta semelhança coletiva, e que, assim, tem sido um dos fundamentos -

2 Os projetos apresentados são, na verdade, fronteiriços, valem-se de métodos e práticas tanto do design quanto da arte. Por isso, há uma indefinição neste trecho, ao se pronunciar o design e a arte como áreas separadas. 
aquele literalmente mais visível - da noção de raça que, atualmente, na segunda metade da primeira década do século XXI, encontra-se num outro estágio de entendimento científico, social, cultural. Raça deixou de ser motivo para discriminação. Mas o que acontece é que há distância entre intenção e gesto, e ainda hoje são muitos e estão em várias partes do mundo (aqui mesmo, onde me encontro neste momento) os conflitos raciais. Nesse contexto, é interessante observar a dubiedade semântica entre a cor da tinta e a cor da pele. A língua portuguesa herdou do latim esse duplo sentido 3 . Segundo um critério histórico e social, diz-se (ainda no presente, infelizmente), por exemplo, no Brasil, das "pessoas de cor" para se referir aos negros afrobrasileiros. Na língua inglesa, dos britânicos, dos estadunidenses (onde a realidade de conflito racial é evidente) e dos sul-africanos (num contexto bem mais difícil), dizia-se, ou ainda se diz, em tom de ofensa, colored (ou coloured). Há ainda, nesses países, a palavra nigger, usada para denegrir (o emprego pleonástico deste verbo aqui é proposital, já que ele também demonstra o preconceito em nossa língua) o negro.

Recusando de saída o preconceito, o que nos importa observar é que pode haver, na percepção das cores de pele, todos os sentidos empregados, nuances, brilhos e opacidades. Além disso, há a cor dos pintores, dos fotógrafos, dos cineastas, dos designers. A cor dos cientistas. Nesse nosso tempo de muitas mídias e muitas possibilidades de pesquisa, conhecimento e desenvolvimento de novos materiais e produtos, a cor do corpo é alvo de constante manipulação. Tecnologias de captura e exibição de imagem e de prototipagem, aplicadas na área médica, fármacos, cosméticos, tinturas, maquiagens, tatuagens etc. acabam por intensificar processos que, em outras épocas, ocorriam (ou eram percebidos) de modos mais sutis.

O corpo, por si, cora ao se emocionar: quantas donzelas, nos romances românticos e nos salões mundanos da Europa do século XIX, por exemplo, enrubesceram ante um aperto de mãos ou um abraço do sujeito amado. Ou mesmo à mesa, nesses mesmos romances e salões, quantos homens e mulheres ruborizaram-se sob o efeito da comida ou da bebida, assim como das emoções, outro fator de alteração da cor facial.

Recordamos aqui um texto de Roland Barthes intitulado "Leituras de Brillat-Savarin", originalmente publicado como apresentação de uma reedição do livro Physiologie du goût, de Brillat-Savarin, cuja edição princeps é de $1825^{4}$.

3 Em um dicionário de latim, por exemplo, color, oris tem, tanto no período arcaico quanto no clássico, as acepções de: a) cor, tinta; b) cor do rosto, tez; c) bonita cor, beleza; além do sentido figurado d) aspecto exterior, cor, aparência; e da retórica e) colorido do estilo.

4 "Jean Anthelme Brillat-Savarin (n. 1 de abril de 1755, Belley, França - f. 2 de fevereiro de 1826, Paris), era um advogado, político e cozinheiro francês. Foi um dos mais famosos epicuristas e gastrônomos franceses de todos os tempos. [...] Publicou várias obras de direito e economia, mas a sua obra mais conhecida foi mesmo Fisiologia do Gosto (Physiologie du goût no original), lançada em dezembro de 1825, dois meses antes da sua morte. [...] Mais do que uma técnica, Brillat-Savarin vê na Gastronomia uma ciência potencial, um conhecimento racional, uma reflexão filosófica (diríamos hoje antropológica, psicológica ou sociológica) sobre a nutrição humana."

Projética, Londrina, v.9, n.2 supl. p. 255-268, nov. 2018 
O texto comenta desta maneira a parte que B.-S. (assim Barthes refere-se ao autor) está descrevendo o prazer (segundo a leitura de Barthes, erótico burguês) de se comer bem, o bem-estar proporcionado tanto pelo alimento, quanto pelo ritual de degustá-lo:

[...] observam-se as mudanças do corpo que se alimenta bem. $O$ índice desse prazer que sobe é, segundo B.-S., uma qualidade temática muito precisa: o brilho; a fisionomia esplende, o colorido se eleva, os olhos se iluminam, enquanto o cérebro se refresca e um suave calor penetra o corpo todo. O brilho é, evidentemente, um atributo erótico: remete ao estado de uma matéria ao mesmo tempo incendiada e molhada, o desejo dando ao corpo o seu lampejo; o êxtase, a sua radiância (a palavra é de B.S.), e o prazer, a sua lubrificação. O corpo do gastrônomo é assim visto como uma pintura levemente radiosa, iluminada do interior. (BARTHES, 2012, p. 318-319).

Essa é uma maneira de perceber a alteração da cor da face e associála ao desejo. O brilho, que também pode ser um atributo de certas emoções (a paixão faz brilhar os olhos do amante), no caso, vem de dentro, do efeito da volúpia causada pelos alimentos. Na maquiagem (pelo menos naquela praticada atualmente no mundo ocidental), o brilho, o blush e outros produtos, devidamente aplicados, segundo um propósito, podem ter também esses mesmos efeitos, ora dos alimentos, ora dos sentimentos, ao acrescentar à pele, por meio da alteração da cor, sutil ou explícita, esse "atributo erótico" de que fala Barthes.

Outras variadas maneiras de acrescentar atributos eróticos ou fetichistas ao corpo são exploradas pelo design, pela arte ou, noutra vertente, pelas ciências biológicas e pela medicina 5 . Da tatuagem ao bronzeamento, da pintura corporal (em seus múltiplos contextos) até as próteses e os implantes, o que se apresenta, cada vez mais, são possibilidades de intervenção no corpo humano, segundo propósitos, por um lado, de aceitação e assimilação do status quo ou, por outro lado, de resistência às forma opressivas de controle do corpo. E, se um corpo transgride a ordem, há sempre dispositivos que o querem reajustar, segundo determinados discursos hegemônicos. Ou simplesmente tratá-lo como um corpo estranho, ao qual se deve evitar.

5 Além disso, levando em conta o outro lado da saúde (de qualquer corpo, aliás, que um dia se acaba) e, há as doenças mais ou menos graves que acometem a pele, causando despigmentação, manchas, erupções, tumores etc. 


\section{FOTOCORPOS}

A fotografia tem sido, desde sempre, um campo de exploração e exposição do corpo humano, em seus mais variados aspectos. Para finalizar este artigo, gostaríamos de apresentar três casos em que fotógrafos e designers realizaram projetos que trabalham a questão da cor relativa ao corpo. Interessanos, por um lado, observar como esses trabalhos apresentam metodologias e práticas pertinentes ao design gráfico, como complemento ao trabalho com a fotografia. E, por outro lado, considerá-los obras que certificam a proposição de Flaviano Celaschi: o corpo como matéria-prima do projeto.

Comecemos pela obra de uma fotógrafa, Angelica Dass. Natural da cidade do Rio de Janeiro, formada em Belas Artes, Dass vive e trabalha em Madri. Em 2015, lançou o projeto Humanae, (DASS, 2017) um work in progress de muito sucesso mundo afora, que traz em sua origem uma ideia aparentemente simples: retratos de pessoas sem qualquer identificação, ao fundo uma cor do catálogo Pantone (2017), e o registro da cor da pele daquela pessoa a partir de um código dessa catalogação: 7522C, 38-8C etc.

Dass (2017) descreve da seguinte maneira o método aplicado ao projeto Humanae: o modelo ou a modelo é fotografado(a), com um fundo branco, depois, é selecionado um quadrante de 11 pixels a partir do nariz e daí é buscada a cor correspondente na paleta industrial Pantone. As redes sociais são o caminho escolhido para divulgação e para seleção de novos modelos. Além disso, exposições físicas foram montadas em renomados museus e em espaços públicos. Como extensão do projeto, percebemos apropriações, por exemplo, de professores, ao desdobrá-lo em aulas de desenho em que cada aluno (no caso relatado, crianças) busca sua própria cor de pele, num autorretrato que tem como base o padrão usado em Humanae (TED..., 2017).

Há, no conceito do projeto, uma postura crítica em relação ao modo como as pessoas são vistas e diferenciadas em razão da cor da pele e, consequentemente, uma denúncia do preconceito que daí deriva.

Humanæ é uma tentativa de ressaltar nossas verdadeiras cores de pele, em vez das falsas: o branco, vermelho, preto ou amarelo, associadas à raça. De repente, eu me dei conta de que esta ideia era útil para muitas pessoas. Representa uma espécie de espelho para aqueles que não se veem refletidos em nenhuma etiqueta. (DASS, 2017).

A potencialidade do projeto, por assim dizer, é que, em princípio, poder-se-ia catalogar todas as pessoas do mundo. Nesse sentido, Alejandro 
Castellote, num texto sobre Humanae, (HUMANAE, 2017) lembra o feito de Alphonse Bertillon, que iniciou o uso do retrato em documentos de identidade, uma ideia logo rápida e mundialmente adotada.

A marca Pantone, por sua vez, faz parte do universo técnico-industrial do design. No projeto de Dass, ainda segundo Castellote, ela oferece certa horizontalidade, proveniente da própria taxonomia do catálogo, que combate a hierarquização das raças pelas cores. Além disso, dilui a própria figura do fotógrafo que, em certa medida, se ausenta como autor, ao definir a obra como um work in progress, embora a obra esteja resguardada por copyright (tal como a marca Pantone), (HUMANAE, 2017) o que, em certo sentido, limita essa horizontalidade defendida por Castellote. No mais, a Pantone é um parceiro do mundo business, seus produtos e serviços são inovadores, hoje é uma marca ímpar no mercado. Em resumo, com elementos da fotografia, metodologias e ferramentas do design e com a parceria da marca certa, Humanae tornouse rapidamente um projeto de sucesso. No site da Pantone, há uma aba do Pantone Institute, que, por sua vez, tem uma área destinada a submissão de propostas, imaginamos que como esta, de Angélica Dass. O que não deixa de ser instigante é pensarmos como uma ideia aparentemente simples, com um resultado plástico também simples, parecido até com outros já vistos, até mesmo no próprio site da Pantone, no ambiente em que são apresentados os trabalhos para outras empresas, como essa ideia baseada na interpretação da cor da pele humana pela fotografia, aliada a um sistema de catalogação de cores, alcançou proporções mundiais. Talvez essa sua raiz no preconceito de cor seja o que lhe tenha dado tamanha força. O sentido da cor da pele, é certo.

O segundo trabalho a nos interessar é o do fotógrafo mineiro Gustavo Lacerda, com seu projeto Albinos. Os albinos são sensíveis à luz, por isso se tornam "invisíveis", segundo Lacerda. O objetivo é torná-los visíveis. São sensíveis também aos olhares de estranhamento que lhes são lançados em público, por serem muito brancos ou "descoloridos". O fotógrafo está ciente disso e, ao torná-los visíveis através de seu trabalho, acaba por forçar um novo pensamento acerca do albinismo, menos de aversão e mais de acolhimento.

Além das exposições físicas e das ferramentas do meio digital, um outro produto, em forma de fotolivro, publicado pela editora Madalena, insere diretamente o design gráfico no projeto. Trata-se de uma edição primorosa, com o projeto, assinado pelo N2 Estúdio, valendo-se de recursos tais como capa dura, dobras, encartes, sobreposição de papéis (folhas de papel vegetal cobrem as páginas, como se a proteger os albinos da luz direta), resultando num objeto harmonioso e que traduz com fidelidade o universo das fotografias dos albinos. 
Figura 1 - Projeto Humanae, de Angelica Daas.

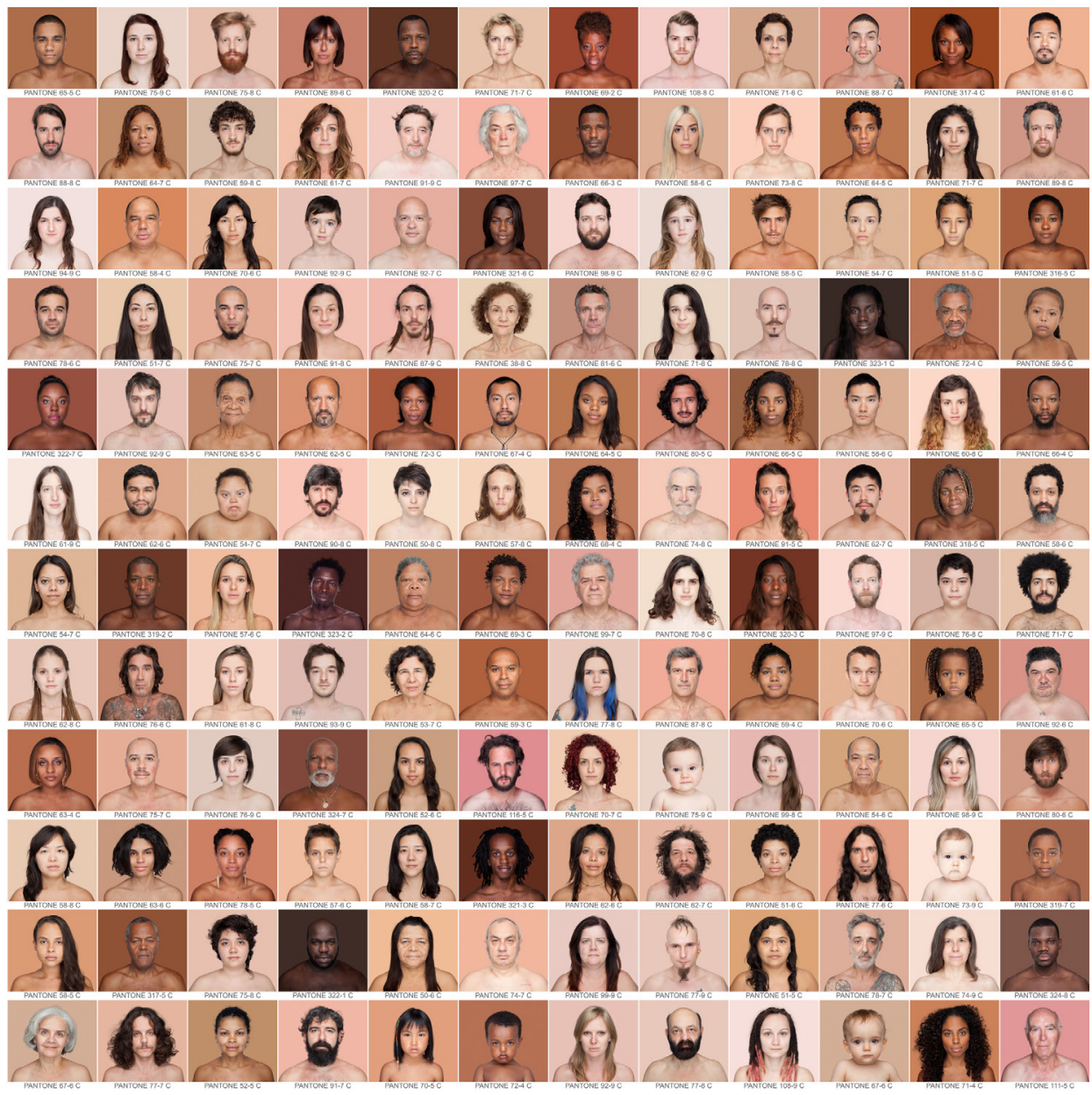

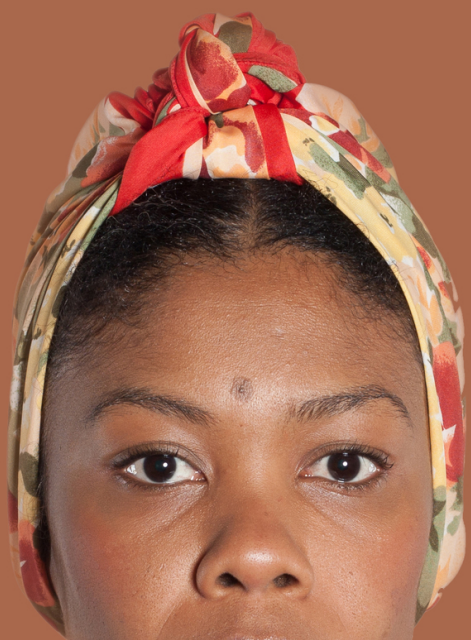

\section{PANTONE $7522 \mathrm{C}$}


Figura 2 - Reprodução de páginas do livro Albinos, de Gustavo Lacerda.
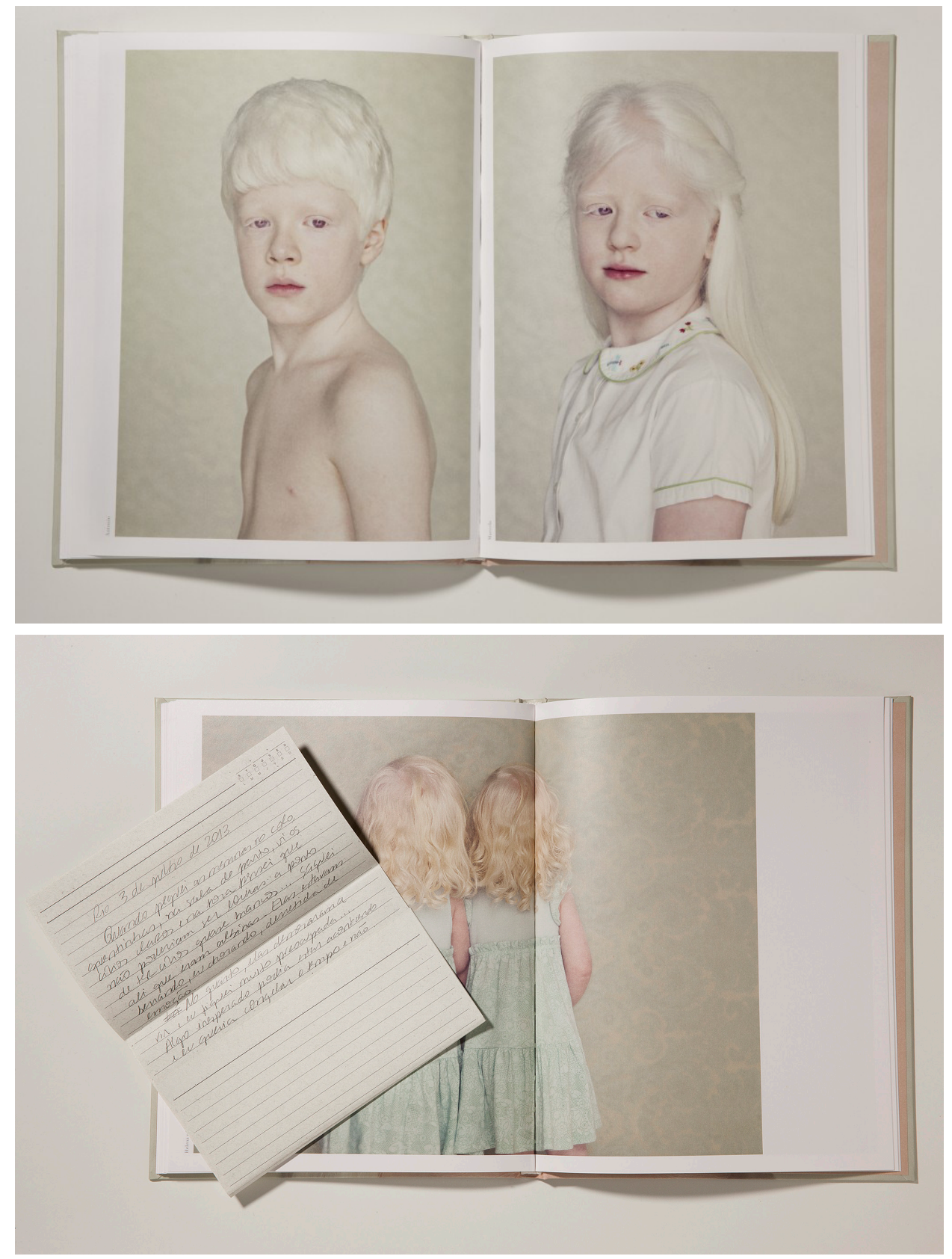

Fonte: Lacerda (2017).

A paleta de cores do livro consegue, de alguma maneira, suavizar a intensidade (causada no meio social) do albinismo. A escolha de crianças (há também homens e mulheres) ajuda a criar um ambiente de aconchego. Os figurinos, as poses, tudo combina com um ar de aceitação. Para os albinos, aceitação à luz, para nós, aceitação do outro como mais um ser de luz.

O terceiro e último caso é o do designer e fotógrafo Rodrigo Bressane. Bressane mantém um estúdio em São Paulo e um site com informações acerca de seus trabalhos, (BRESSANE, 2017) em que são apresentados projetos divididos em quatro categorias: sardas, tatuagens, bodypainting e banco de imagens. Bodypainting é apresentado por meio de imagens e de um texto em forma de pergunta e resposta, num tom coloquial e despretensioso, diferente daquilo 
que percebemos no trabalho de Angélica Dass, em que há um tom mais formal e consistente, na apresentação textual dos projetos. Sua execução envolve o pintor (no caso, um designer de formação, Luís Matuto), modelos (por algum motivo que não é exposto, apenas mulheres, e ainda dentro de determinado perfil de beleza) e o fotógrafo, num ensaio em que o corpo da modelo é, mais do que o meio, a pele da escrita, segundo uma prática tão antiga.

As fotografias nunca são de corpo inteiro, sempre nos são mostradas partes do corpo, o que nos remete a uma característica própria ao fetiche (pensando naquela vertente apontada por Rafael Cardoso, do designer como fetichista): a abstração, "compreendida aqui, de maneira bastante peculiar, como ato de abstrair-se da 'totalidade da pessoa' a fim de fixar em um traço isolado ou em um objeto que lhe seja contíguo". (SAFATLE, 2015, p. 40). Segundo essa linha de pensamento, instaurada no início dos estudos da psicologia, todo sujeito amoroso é um fetichista. Diríamos que o ato do fotógrafo de (de)compor o corpo e, com isso, compor uma imagem cuja finalidade é um "deslocamento metonímico", desperta o olhar da abstração e do fetiche. Na foto abaixo, percebe-se, além da pintura corporal que cobre as mãos em primeiro plano, o colo e o pescoço, o rosto coberto de maquiagem (batom na boca, delineador nos olhos) e a sobrancelha desenhada segundo princípios do visagismo. Se a pintura traz um estranhamento (no bom sentido da "inquietante estranheza", daquilo que assusta por atrair) à imagem, pelos grafismos e pela cobertura que a tinta dá à pele, a maquiagem trabalha no registro do familiar, algo que já nos acostumamos a entender como sedutor numa figura feminina, seja pela fotografia, pelo cinema ou pela moda.

Figura 3 - Reprodução de fotografia do projeto Bodypainting.

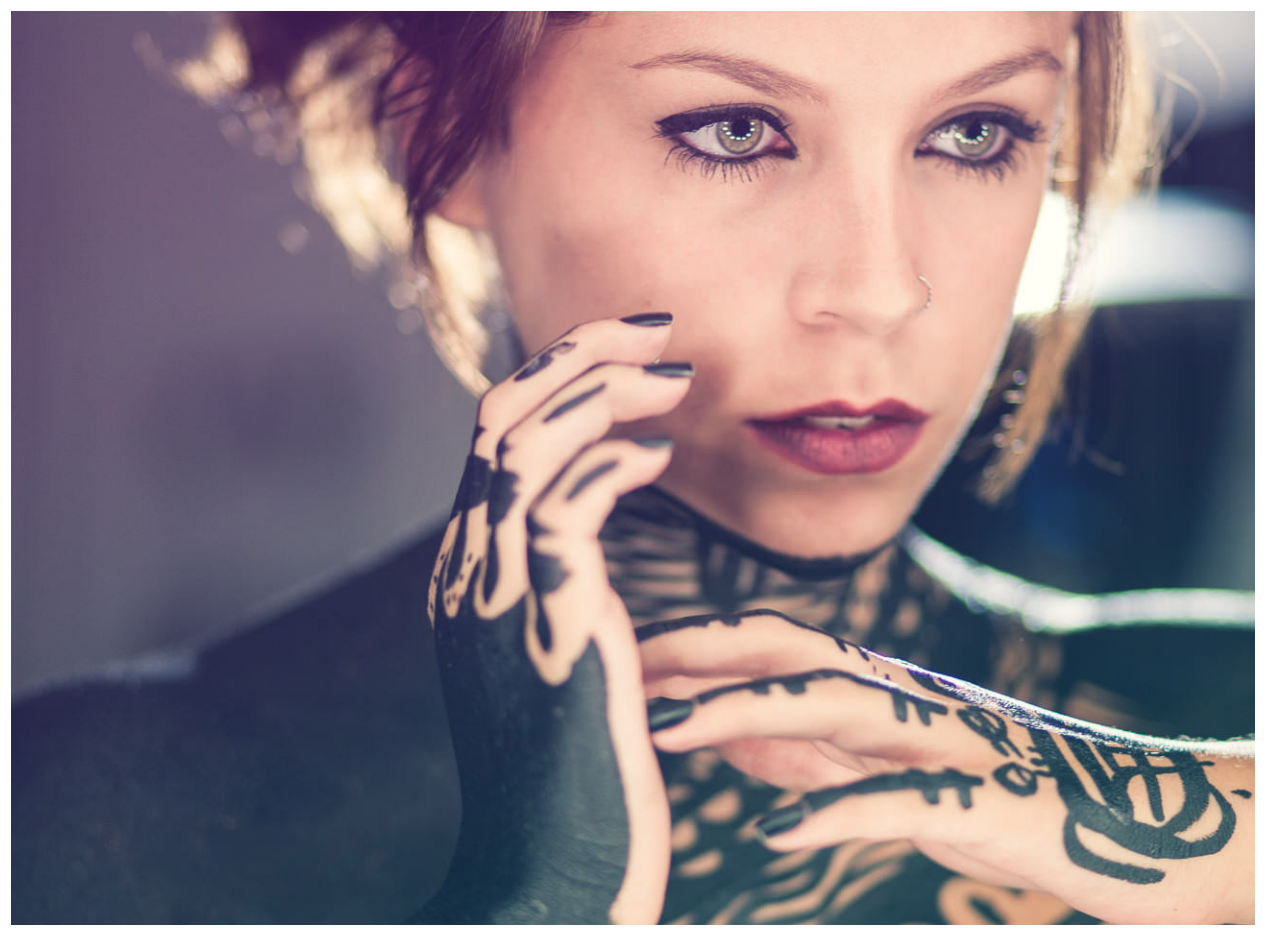

Fonte: Bressane (2017). 
Tal como nesse projeto, embora sem a presença da pintura, "Sardas" tem o foco na pele, suas marcas e seus cuidados. De forma breve, o texto defende que a ideia "é mostrar a beleza da modelo com ênfase nas expressões e pele". Assim como Humanae tem a pretensão de desafiar a noção de raça e a discriminação de cor que ainda existe no mundo, poderíamos afirmar que, ao mostrar a beleza da sarda, Bressane acaba por se opor a um discurso que hoje, em nosso contexto, é defendido pela grande indústria de fármacos e cosméticos, junto com certa área médica, qual seja, o da "limpeza" da pele: nada de manchas, pintas (é verdade, precisamos relevar, há o risco real de elas serem cancerígenas) ou rugas. A ideia é que sejam apagados os sinais do tempo, removidas as cicatrizes das feridas da vida. Contra a flacidez, a ordem é que a tez seja (para sempre) rígida e jovial. No âmbito da fotografia, o advento das ferramentas digitais acabou por proporcionar mais facilidade de retoques e "limpezas", de modo a corroborar com esse discurso, nas grandes mídias de massa.

Entretanto, nesse rol de limpeza, parece-nos que há certa aceitação justamente pelas sardas - aquelas das ruivas (já que estamos falando de um fotógrafo que, curiosamente, nesses projetos apresentados, só retrata mulheres), cuja imagem, nesse mesmo campo discursivo, é fetichizada por meio da cor do cabelo (o fogo da paixão), da pele (a brancura angelical) e das próprias sardas (a novidade, os desenhos inesperados). O mesmo tem acontecido, nos últimos anos, na moda, em que modelos com o tom de pele muito negro (chamadas pela imprensa ligada aos eventos da moda de "supermelaninadas") ou muito brancos, ou com vitiligo - pessoas que, no dia a dia de suas vidas, em algum momento sofrem preconceitos - são valorizadas, num movimento de inversão que a moda (o design, a arte) produz, aproveitando, para o bem e para o mal, à vezes, o clichê do "exótico" para atrair o consumidor, que, ao mesmo tempo, estranha e admira o diferente e outrora feio colocado naquele lugar de beleza.

\section{CONCLUSÃO}

A fotografia é luz, e a luz é o alimento da cor 6 . Com camadas de conhecimento artístico e científico acumuladas ao longo dos tempos, temos hoje inúmeras possibilidades de trabalhar a cor no campo da fotografia e de entender como as cores afetam nossa percepção. O olhar e a câmera do fotógrafo, ao se voltarem para a cor do corpo, capturam não somente a ação da luz sobre aquele corpo (a sensação da cor), mas também a psicologia e a cultura humana (a percepção da cor) relativas ao contexto em que o corpo se insere. Negros ainda são discriminados por serem negros; sardas e manchas, por vezes marcas da

6 Segundo a definição de Israel Pedrosa (2013, p. 20): “A cor não tem existência material: é apenas sensação produzida por certas organizações nervosas sob a ação da luz - mais precisamente, é a sensação provocada pela ação da luz sobre o órgão da visão." 
velhice, são combatidas pela indústria cosmética, em nome do consumo de um ideal de beleza hegemônico; albinos, em algumas regiões da África, são perseguidos e mortos por grupos que creditam poderes mágicos (segundo uma primeira vertente do fetiche) a seus ossos. Tudo isso são construções socioculturais cujos trabalhos dos designers e artistas que aqui apresentamos buscam desconstruir, ao nos mostrar, com outros olhos, pautados pela estética - no caso, pelo "desvio pela luz", que é, segundo Jacques Aumont (2004, p. 172), "o primeiro operador formal e, potencialmente, plástico" da fotografia - e pela ética, que, para além da cor da pele, está a dignidade humana.

A amostragem dos casos apresentados neste artigo, por sua vez, buscou chamar a atenção para o fato de que cada um deles, na realização dos projetos, aplicou metodologias e ferramentas que identificamos como de design. Ou seja, com esses exemplos, tentamos demonstrar que, mesmo estando no campo da arte, projetos como esses podem muito bem fazer parte do rol de trabalhos de um bom designer.

Colocar o corpo no centro do projeto de design é, portanto, defender o humanismo, tal como nos ensina Celaschi. E, estando nossos corpos constantemente submetidos a vigilâncias e repressões, as intervenções como estas, no campo da fotografia e do design, e outras, talvez mais radicais, no campo da arte, podem, se não nos livrar dos dispositivos que nos controlam, nos dar, ao menos, a chance de desnudarmos alguns "corpos indóceis".

\section{REFERÊNCIAS}

AUMONT, Jacques. A estética do filme. São Paulo: Papirus, 2004.

BARTHES, Roland. O rumor da língua. São Paulo: M. Fontes, 2012.

BRESSANE, Rodrigo. Projetos. Disponível em: <http://www.bressane.com/ projetos/>. Acesso em: 5 nov. 2017.

CELASCHI, Flaviano. O corpo como matéria-prima do projeto. In: MORAES, Dijon de; MARTíNEZ, Sergio Luis Peña. Cadernos de estudos avançados em design: cultura. Belo Horizonte: EdUEMG, 2016. p. 57-70.

DASS, Angélica. Photography. Disponível em: <http://www.angelicadass. com/>. Acesso em: 14 nov. 2017.

GERMAK, Claudio (Org.). Uomo al centro del progetto: design per un nuovo umanesimo. Turim: U. Allemandi, 2008.

HUMANAE. Work in progress. Disponível em: < http://humanae.tumblr.com/ about>. Acesso em: 5 nov. 2017. 
LACERDA, Gustavo. Albinos. Disponível em: <http://estudiomadalena.com.br/ albinos-gustavo-lacerda/>. Acesso em: 5 nov. 2017.

NASIO, Juan David. Meu corpo e suas imagens. Rio de Janeiro: Zahar, 2009.

PANTONE. Featured products. Disponível em: < www.pantone.com>. Acesso em: 14 nov. 2017.

PEDROSA, Israel. Da cor à cor inexistente. Rio de Janeiro: Senac Nacional, 2013.

SAFATLE, Vladimir. Fetichismo: colonizar o outro. Rio de Janeiro: Civilização Brasileira, 2015. (Para ler Freud).

TED ideas Worth spreading. Disponível em: <https://www.ted.com/talks/ angelica_dass_the_beauty_of_human_skin_in_every_color?nolanguage $=+$ ptbr\#t-263934>. Acesso em: 5 nov. 2017.

VERAS, Marcelo. Home. Disponível em: <https://www.marceloveras.com/>. Acesso em: 14 nov. 2017. 